\title{
Diabetes Self-Management Education and Practices among Type 2 Diabetic Patients
}

\author{
Muhammad Sajid Abbas Jaffri, Saja Riyaz, Sara Riyaz, Mah Rida \\ ABSTRACT
}

Objective: To compare the knowledge and practices of diabetes self- care management among type 2 diabetic patients in two hospitals of Karachi.

Study Design and Setting: A cross sectional study was carried out at two Tertiary Care Hospital of Karachi from March 2018 to August 2018.

Methodology: A total of 120 subjects of type 2 diabetes were included in the study. Data was collected through structured questionnaire. Knowledge regarding diabetes includes normal blood sugar level, symptoms of low and high blood sugar and management of these symptoms. Structured questionnaire was used to collect information of sociodemographic characteristics, knowledge and attitude of diabetes and self-care management practices. Data was analyzed by SPSS version 21. P value less than 0.05 considered as significant

Results: Majority of the participants were females (55\%) and males were (45\%).The duration of diabetes in majority of participants, $(43.3 \%)$ was less than 5 years. From total $53.3 \%$ of our study participants were aware about the knowledge of diabetic complications. Approximately ,59.6\% participants thought visit to eye specialist is important and about $44.16 \%$ thought that monthly visit to hospital for general health is important for diabetic patients. When asked about early signs of development of complications $48.3 \%$ participants thought that development of foot ulcers, $83 \%$ thought diabetes was strongly associated with obesity. Total, $76.6 \%$ participants thought that plan of meal is important. Total, $30.83 \%$ participants were in agreement with this thought that diabetes was strongly associated with obesity.

Conclusion: The knowledge of self-care practices in diabetic patients was average in this study.

KEY WORDS: Diabetes Complications, Diabetes mellitus, Diabetes self-management education (DSME).

\section{INTRODUCTION:}

Diabetes mellitus (DM) is a medical condition characterized by chronic hyperglycemia resulting from defects in insulin secretion, insulin action, or both. This may lead to longterm complications microvascular or macrovascular which includes damage, dysfunction and failure of various organs, in particular the eyes, kidneys, nerves, heart and blood vessels. Type 2 diabetes occur most commonly due to inability of the body to use insulin properly, resulting in increased blood glucose levels. ${ }^{1}$

Diabetes self-management education (DSME) is defined as "the process of facilitating the knowledge, skill, and ability necessary for diabetes self-care" ${ }^{11}$.Diabetes self-management education (DSME), the process of teaching individuals to

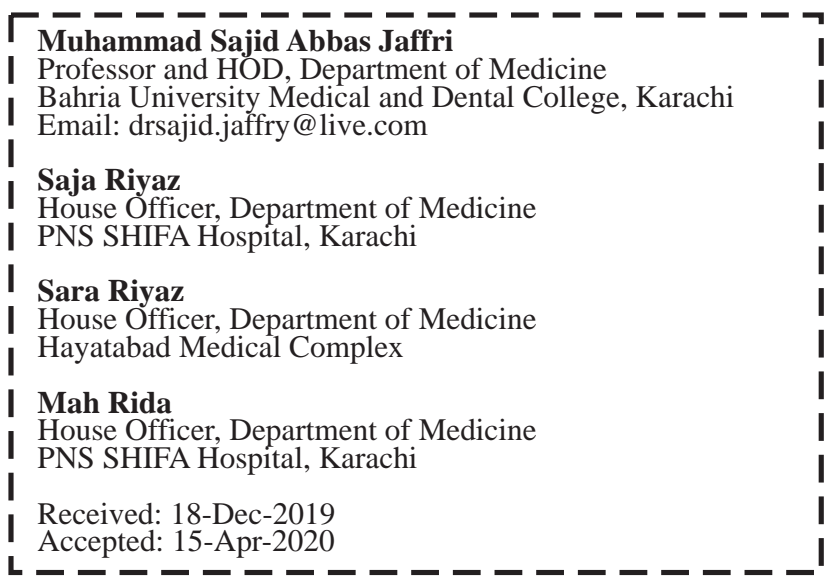

manage their diabetes, has been considered an important part of the clinical management of individuals with diabetes. ${ }^{2}$ DSME provides informed support, self-care and selfmanagement instructions in order to improve quality of life and decreases the probability of diabetes complications.

It was estimated that in 2017 there were 451 million (age 18-99 years) people with diabetes worldwide. These figures were expected to increase to 639 million by $2045 .^{3}$ In Pakistan approximately $7.89 \%$ populations is affecting with diabetes mellitus per annum. In this context, Pakistan is ranked seventh in diabetes prevalence. ${ }^{4}$ Diabetes prevalence has been rising more rapidly in middle and low-income countries. According to $\mathrm{WHO}$, the global prevalence of diabetes is $8.5 \%$ in 2014 and the burden of diabetes has doubled from 1980 to 2014.Several studies revealed that lifestyle modification in obese patient has been effective in achieving a very good glycemic control. ${ }^{5}$ A study in Malaysia shows that public hospitals having specialist diabetologist were more inclined towards treating the complication of diabetes while in public health clinics having general practitioners for the treatment of diabetes, only focused on controlled blood pressure and HbA1c under normal ranges. ${ }^{6}$ The mortality risk of Type 2 can be reduced by DSME among type 2 DM patients. ${ }^{7}$ In a review including 118 unique interventions reported significant changes (61.9\%) in A1C. Overall mean reduction in $\mathrm{A} 1 \mathrm{C}$ was observed from 0.74 and 0.17 in intervention and control groups; as average absolute reduction in $\mathrm{A} 1 \mathrm{C}$ of $0.57 .^{8}$ 
In a study of DSME programs among older adults revealed an absolute reduction in $\mathrm{HbA}(1 \mathrm{c})$, lipid profile and blood pressure. ${ }^{9}$ The study by Sherifali $\mathrm{D}^{9}$ depicted that DSME programs improves the clinical outcomes by maintaining the blood pressure and lipid profile, and eventually improves the health status and quality of life of an individual. ${ }^{10}$ DSME programs required proper assessment, interactive teaching methods and multidisciplinary approach. ${ }^{11}$ The coordinated model of care can be helpful to meet the growing demand of proper accessibility and utility of DSME programs. ${ }^{11}$ Some studies reflected that there was marked effect of DSME on diabetes distress , despite of limited participation in DSME programs. ${ }^{12}$

Therefore, this study was aimed to assess the knowledge of DSME among diabetic patient. The outcome of this study would assist to evaluate the awareness of DSME among diabetic patients which has an important role to prevent the diabetes progression and to reduce the seious threat to the life of diabetic patients worldwide.

\section{METHODOLOGY:}

A cross sectional study was carried out in PNS Shifa and National Medical Centre Karachi from March 2018 to August 2018 after obtaining approval from IRB BUMDC (No: 562018). The sample size calculated was 120 through open epi at $95 \%$ confidence interval with a significance level of $5 \%$ at global prevalence of $8.5 \% .{ }^{04}$ Non-probability purposive sampling was used to collect data. Verbal consent was obtained after explaining the rationale of the study. Inclusion criteria consisted of Patients with Type 2 diabetes having diabetes for more than 6 months; sociodemographic variables used were age, gender, occupation, weight and BMI. Knowledge regarding diabetes includes normal blood sugar level, symptoms of low and high blood sugar and management of these symptoms. Structured questionnaire was used to collect information of sociodemographic characteristics, knowledge and attitude of diabetes and selfcare management practices. Data was analyzed by SPSS version 21. Frequencies and percentages were used to express categorical variables. For quantitative variables mean and standard deviation was used. Chi square test was used and $\mathrm{p}$ value less than 0.05 was considered as statistically significant.

\section{RESULTS:}

Total 120 participants fulfilled the inclusion criteria from which $(55 \%)$ were females and $(45 \%)$ were males. Equal number of participants were taken from PNS Shifa hospital $\mathrm{n}=60$ and National medical center (NMC) $\mathrm{n}=60$.The included age stratification groups were from 37 to above 70 years. Total $14 \%$ were from age group 37-47 years (PNS Shifa $=15 \%$ $\mathrm{NMC}=13.3 \%$ ), age $48-57$ were $49.1 \%$ (PNS Shifa $=45 \%$ $\mathrm{NMC}=53.3 \%$ ), $30 \%$ were from age group 58-67 (PNS Shifa $=36.7 \%, \mathrm{NMC}=23.3 \%$ ) and $6.6 \%$ were from age above 70 years (PNS Shifa $=3.3 \%$ NMC $=10 \%)$.
The duration of diabetes in majority of participants was less than 5 years as $(43.3 \%),(25.8 \%)$ had 5-10 years of duration, (20\%) had the duration of $10-15$ years, $(10.8 \%)$ had duration of 15-20 years. Out of these 120 participants almost half (50.8\%) were diagnosed incidentally as type $2 \mathrm{DM}$ whereas (39.2\%) participants went to the hospital upon appearance of symptoms other (3.3\%) were diagnosed with oral glucose tolerance test and (6.7\%) did not exactly remember. Treatment taken by majority of participants was insulin $n=26, n=72$ on oral hypoglycemic, $n=17$ on both and $n=5$ took no treatment. When they were asked about insulin storage $81 \%$ from NMC and $92 \%$ from PNS Shifa hospital were aware to keep insulin in refrigerator. (Table-1).

About $53.3 \%$ participants were aware of symptoms and complications of diabetes and about 35\% of participants were not aware of complications others didn't know neither thought it is important to know about complications. 59.6\% participants thought visit to eye specialist is important and about $44.16 \%$ thought that monthly visit to hospital for general health is important for diabetic patients. When asked about early signs of development of complications $48.3 \%$ participants thought that development of foot ulcers and infections is the early sign and $14.16 \%$ thought recurrent urinary tract infection is the early sign and $24.16 \%$ were in agreement with both important signs of development of complications. When asked about care of feet $61.6 \%$ thought that care of feet is important and $38.3 \%$ participants were dis agree with importance of foot care. $\mathrm{n}$ our study about 76.6\% participants thought that plan of meal is important. Total, $30.83 \%$ participants were in agreement with this thought that diabetes was strongly associated with obesity. Practice of DSME program was shown in table-2.

\section{DISCUSSION:}

Diabetes mellitus is considered as an emerging public health issue due to the global increase in the case incidence of diabetes. In our study majority of participants were female making 55\% of the total participants in both health care systems. In our study, the duration of diabetes in majority of participants was less than 5 years as $(43.3 \%),(25.8 \%)$ had 5-10 years of duration, (20\%) had the duration of 10 15 years, (10.8\%) had duration of 15-20 years and these results are are consistent with the results of a study conducted by Muhammad Umar Ahmad et al. ${ }^{13}$

An important finding in our study was that the respondents have a good knowledge about diabetes and its selfmanagement practices, which was opposite to the study done by Muhammad Umar Ahmed et al ${ }^{13}$ according to which participants have poor knowledge of DSME.

In our study about $76.6 \%$ participants thought that plan of meal is important which is important to have a good glycemic control which was shown in a study conducted by Xuelian Jiang et al. in which participants were divided in control and intervention group after a period of 12 month intervention 
Diabetes Self-Management Education and Practices among Type 2 Diabetic Patients

Table:1- Knowledge of Diabetes regarding DSME among two different Health Care Systems.

\begin{tabular}{|c|c|c|c|c|}
\hline & \multirow[b]{2}{*}{ Responses } & \multicolumn{2}{|c|}{ Place of Study } & \multirow[b]{2}{*}{ P-value } \\
\hline & & $\underset{(n=60)}{\mathrm{NMC}}$ & 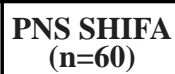 & \\
\hline \multirow{2}{*}{ Normal blood sugar level. } & Yes & $43(71.7 \%)$ & $44(73.3 \%)$ & \multirow{2}{*}{0.988} \\
\hline & No & $17(28.3 \%)$ & $16(26.7 \%)$ & \\
\hline \multirow{2}{*}{$\begin{array}{l}\text { Do you know symptoms of low } \\
\text { sugar? }\end{array}$} & Yes & $55(91.7 \%)$ & $53(88.3 \%)$ & \multirow{2}{*}{0.762} \\
\hline & No & $5(8.3 \%)$ & $7(11.7 \%)$ & \\
\hline \multirow{4}{*}{ Symptoms of low blood sugar. } & Lethargy & $34(56.7 \%)$ & $44(73.3 \%)$ & \multirow{4}{*}{0.071} \\
\hline & Confusion & $15(25.0 \%)$ & $5(8.3 \%)$ & \\
\hline & Palpitation & $6(10.0 \%)$ & $4(6.7 \%)$ & \\
\hline & Sweating & $5(8.3 \%)$ & $7(11.7 \%)$ & \\
\hline \multirow{4}{*}{ Manage of low blood sugar. } & Take sweets & $37(61.7 \%)$ & $48(80.0 \%)$ & \multirow{4}{*}{0.081} \\
\hline & Drink juices & $12(20.0 \%)$ & $9(15.0 \%)$ & \\
\hline & Eats bread & $8(13.3 \%)$ & $2(3.3 \%)$ & \\
\hline & Eat fruits & $3(5.0 \%)$ & $1(1.7 \%)$ & \\
\hline \multirow{2}{*}{$\begin{array}{l}\text { Do you know symptoms of } \\
\text { high blood sugar? }\end{array}$} & Yes & $57(95.0 \%)$ & $55(91.7 \%)$ & \multirow{2}{*}{0.717} \\
\hline & No & $3(5.0 \%)$ & $5(8.3 \%)$ & \\
\hline \multirow{4}{*}{$\begin{array}{l}\text { Symptoms of high blood sugar } \\
\text { level. }\end{array}$} & Increased thirst & $12(20.0 \%)$ & $14(23.3 \%)$ & \multirow{4}{*}{0.493} \\
\hline & Visual blurring & $14(23.3 \%)$ & $9(15.0 \%)$ & \\
\hline & Leg pain & $11(18.3 \%)$ & $8(13.3 \%)$ & \\
\hline & Increased urination & $23(38.3 \%)$ & $29(48.3 \%)$ & \\
\hline
\end{tabular}

Table: 2- Practices of DSME among Diabetes patients of two different Health Care Systems

\begin{tabular}{|c|c|c|c|c|}
\hline & Responses & $\begin{array}{c}\text { NMC } \\
(n=60)\end{array}$ & $\underset{(n=60)}{\text { PNS SHIFA }}$ & P-value \\
\hline \multirow{2}{*}{$\begin{array}{l}\text { Control of sugar by only diet or along with } \\
\text { medicine }\end{array}$} & Yes & $42(70.0 \%)$ & $43(71.7 \%)$ & \multirow{2}{*}{0.936} \\
\hline & No & $18(29.7 \%)$ & $17(26.3 \%)$ & \\
\hline \multirow{2}{*}{ Plan of meal } & Yes & $42(70.0 \%)$ & $50(83.3 \%)$ & \multirow{2}{*}{0.130} \\
\hline & No & $18(30.0 \%)$ & $10(16.7 \%)$ & \\
\hline \multirow{4}{*}{ Proportion of meal } & Vegetables/fruits & $46(76.7 \%)$ & $48(80.0 \%)$ & \multirow{4}{*}{0.841} \\
\hline & Oils & $8(13.3 \%)$ & $9(15.0 \%)$ & \\
\hline & Only sea food and nuts & $1(1.7 \%)$ & $0(0.0 \%)$ & \\
\hline & Only poultry & $5(8.3 \%)$ & $3(5.0 \%)$ & \\
\hline \multirow{4}{*}{ Association with obesity } & Strong association & $18(30.0 \%)$ & $19(31.7 \%)$ & \multirow{4}{*}{0.795} \\
\hline & Weak association & $1321.7 \%$ & $16(26.7 \%)$ & \\
\hline & No association & $8(13.3 \%)$ & $9(15.0 \%)$ & \\
\hline & Don't know & $21(35.0 \%)$ & $16(26.7 \%)$ & \\
\hline \multirow{4}{*}{ Engage in physical activity } & daily & $27(45.0 \%)$ & $31(51.7 \%)$ & \multirow{4}{*}{0.075} \\
\hline & Alternate days & $7(11.7 \%)$ & $11(18.3 \%)$ & \\
\hline & Weekly & $3(5.0 \%)$ & $7(11.7 \%)$ & \\
\hline & Monthly & $23(38.3 \%)$ & $11(18.3 \%)$ & \\
\hline \multirow{4}{*}{ Mode of physical activity } & Gym workout & $6(10.0 \%)$ & $2(3.3 \%)$ & \multirow{4}{*}{0.044} \\
\hline & Brisk walking & $53(88.3 \%)$ & $51(85.0 \%)$ & \\
\hline & Cycling & $0(0.0 \%)$ & $5(8.3 \%)$ & \\
\hline & Swimming & $1(1.7 \%)$ & $2(3.3 \%)$ & \\
\hline
\end{tabular}


group had good glycemic control. ${ }^{5}$

Proper storage of insulin is very necessary for its efficacy according to a research conducted by Chakraborty $\mathrm{P} \mathrm{et} \mathrm{al}{ }^{14}$ which evidenced that errors in insulin therapy can result in failure of insulin efficacy and improper storage can result in expiration of insulin before time. In our study $21.6 \%$ participants were on only insulin therapy and $14.1 \%$ were on both oral and insulin and $97.6 \%$ were having knowledge that insulin should be stored in refrigerator which shows that participants have enough knowledge that proper storage of drug is important. ${ }^{14}$

In our study, $30.83 \%$ thought diabetes was strongly associated with obesity which depicted that people are less aware of association of diabetes with obesity. These results were comparable with the study conducted in India ${ }^{15}$ which showed that occurrence of type 2 diabetes is very much common in people who are obese and is less common in those who are non-obese.

In our study, $48.3 \%$ thought that engaging in physical activities plays a significant role in a good control of diabetes which is beneficial for maintaining proper health in a diabetic person and these results are consistent with a study which showed that physical activity is critically focus for blood glucose management in individuals with diabetes and prediabetes. ${ }^{16}$

It is well known that foot care is important for a diabetic patient. ${ }^{17}$ In our study, $53.3 \%$ participants agreed that foot protection can prevent from diabetic foot and non-healing infections and these results were higher than reported in a study which showed that $36.6 \%$ participants practiced selffoot care. ${ }^{17}$

The knowledge of participants about the importance of eye screening in a diabetic person was observed in our study and $59.16 \%$ participants responded positively and thought that eye checkup is very important this result was very similar to the study of Kazi Rumana Ahmed conducted in Bangladesh and showed that almost $50 \%$ of participants were aware of importance of eye screening. ${ }^{18}$

In our study, 53.3\% of participants were aware about the knowledge of diabetic complications which was good enough when compared to a study in Ghana which revealed that $60 \%$ of participants had no knowledge about complications of diabetes mellitus. ${ }^{19-20}$ However, the small sample size was the limitation of our study and further multi centered and case control studies are recommended. While the rising burden of diabetes, there is a dire need to address the awareness of Diabetes self-management education (DSME) in the health care systems and also focused on community level hence the major goal is to educate the population regarding the complications of diabetes to prevent the disabilities.

\section{CONCLUSION:}

The knowledge of self-care practices in diabetic patients was average in this study. With the increasing burden of diabetes in Pakistan the knowledge and attitude of people is augmenting towards diabetes.

\section{REFERENCES:}

1. Powers, M., Bardsley, J., Cypress, M., Duker, P., Funnell, M., Hess Fischl, A., Maryniuk, M., Siminerio, L. and Vivian, E. (2015). Diabetes Self-Management Education and Support in Type 2 Diabetes: A Joint Position Statement of the American Diabetes Association, the American Association of Diabetes Educators, and the Academy of Nutrition and Dietetics. Journal of the Academy of Nutrition and Dietetics, 115(8), pp.13231334.

2. Task Force to Revise the National Standards: National standards for diabetes self-management education programs. Diabetes Educ 21:189-193

3. Cho, N., Shaw, J., Karuranga, S., Huang, Y., da Rocha Fernandes, J., Ohlrogge, A. and Malanda, B. (2018). IDF Diabetes Atlas: Global estimates of diabetes prevalence for 2017 and projections for 2045. Diabetes Research and Clinical Practice, 138, pp.271-281.

4. Ali I, Hussain A. Diabetes mellitus in Pakistan: A major public health concern. Archives of Pharmacy Practice. 2016;7(1):30.

5. Jiang X, Fan X, Wu R, Geng F, Hu C. The effect of care intervention for obese patients with type II diabetes. Medicine. 2017;96(42):e7524

6. Chew B,Shariff-GhazaliS,LeeP,CheongA,MasturaI,HaniffJ,et al .Type 2 Diabetes Mellitus Patient Profiles,Diseses Control and Complications at Four Public Health Facilities-A Crosssectional Study based on the Adult Diabetes Control and Management (ADCM) Registry 2009.Medical Journal of Malaysia.2013;68(5):397-404.

7. He X,LiJ,WangB, YaoQ,LiL,Song R et al.Diabetes selfmanagement education reduces risk of all-cause mortality in type 2 diabetes patients:a systematic review and meta analysis.Endocrine.2016;55(3):712-731.

8. Chrvala C, Sherr D, Lipman R. Diabetes self-management education for adults with type 2 diabetes mellitus: A systematic review of the effect on glycemic control. Patient Education and Counseling. 2016;99(6):926-943.

9. Sherifali D, Bai J, Kenny M, Warren R, Ali M. Diabetes selfmanagement programmes in older adults: a systematic review and meta-analysis. Diabetic Medicine. 2015;32(11):14041414

10. Haas,M.Maryniuk,J.Beck,C.E.Cox,P.Duker,L.Edwards, Fisher,L.Hanson,D.Kent,L.Kolb,S.Mclaughlin,E.Orzeck,J. D.Piette,A.S.Rhinehart,R.Rothman,S.Sklaroff,D.Tomky,G. Youssef,National standards for self-management education and support.Diabetyes.Care.37(Suppl 1),S144-S153(2014)

11. Mardanian Dehkordi L, Abdoli S. Diabetes Self-Management Education; Experience of People with Diabetes. Journal of Caring Sciences. 2017;6(2):111-118.

12. Santorelli M, Ekanayake R, Wilkerson-Leconte L. Participation in a Diabetes Self-Management Class Among Adults With Diabetes, New Jersey 2013-2015. Preventing Chronic Disease. $2017 ; 14$ 
13. Ahmed M, Seriwala H, Danish S, Khan A, Hussain M, Husain $\mathrm{M}$ et al. Knowledge, Attitude, and Self Care Practices Amongsts Patients WithType 2 Diabetes in Pakistan. Global Journal of Health Science. 2015;8(7):1

14. Chakraborty P, Chowdhury S. Errors of insulin therapy: Reallife experiences from developing world. Journal of Family Medicine and Primary Care. 2017;6(4):724.

15. Babu G, Murthy G, Ana Y, Patel P, R D, Neelon S et al. Association of obesity with hypertension and type 2 diabetes mellitus in India: A meta-analysis of observational studies. World Journal of Diabetes. 2018;9(1):40-52.

16. Colberg S, Sigal R, Yardley J, Riddell M, Dunstan D, Dempsey $P$ et al. Physical Activity/Exercise and Diabetes: A Position Statement of the American Diabetes Association. Diabetes Care. 2016;39(11):2065-2079.

17. Mariam T, Alemayehu A, Tesfaye E, Mequannt W, Temesgen $\mathrm{K}$, Yetwale F et al. Prevalence of Diabetic Foot Ulcer and Associated Factors among Adult Diabetic Patients Who Attend the Diabetic Follow-Up Clinic at the University of Gondar Referral Hospital, North West Ethiopia, 2016: InstitutionalBased Cross-Sectional Study. Journal of Diabetes Research. 2017;2017:1-8.
18. Ahmed K, Jebunessa F, Hossain S, Chowdhury H. Ocular knowledge and practice among type 2 diabetic patients in a tertiary care hospital in Bangladesh. BMC Ophthalmology. $2017 ; 17(1)$

19. Obirikorang Y, Obirikorang C, Anto E, Acheampong E, Batu E, Stella A et al. Knowledge of complications of diabetes mellitus among patients visiting the diabetes clinic at Sampa Government Hospital, Ghana: a descriptive study. BMC Public Health. 2016;16(1)

20. Saleh F, Mumu S, AraF, Begum H, Ali L. Knowledge and self-care practices regarding diabetes among newly diagnosed type 2 diabetes I Bangladesh: a cross section study.BMC Public Health.2012;12(1).

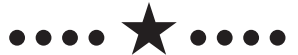

